\title{
A Dermatologia nas Artes Visuais
}

Ricardo Vieira, MD, PhD

Serviço de Dermatologia, Centro Hospitalar e Universitário de Coimbra, Coimbra, Portugal

\section{Dermatological Expression in Visual Arts}

A iconografia reveste-se de grande importância em Dermatologia. O recurso a diversas formas de expressão imagética tem sido recorrente ao longo dos tempos, não apenas para registo semiológico ou para fins nosográficos, mas principalmente para fins académicos e pedagógicos. Desenhos, aguarelas, representações ceroplásticas, fotografias e vídeos: a iconografia dermatológica foi sofrendo transformações ao sabor da evolução tecnológica, servindo meramente propósitos científicos, para os quais foram concebidas sem preocupações artísticas. Não sendo a definição de arte estanque nem independente de uma contextualização temporal, estas imagens científicas afastam-se claramente da natureza da arte expressada ironicamente por Oscar Wilde no prefácio de "O Retrato de Dorian Gray": "Toda a arte é perfeitamente inútil". Assim, abordar a presença da Dermatologia nas artes visuais é ir para além da iconografia científica, em direção à representação pictórica, fotográfica e cinematográfica, realizada apenas como objeto ou tema da arte. São inúmeros os exemplos e, sem sermos exaustivos, encontramos miríades destas alusões, abarcando várias disciplinas da especialidade.

"A morte de Marat" de Jacques-Louis David (1793) é uma tela a óleo que representa o revolucionário radical francês Jean-Paul Marat assassinado (fora apunhalado por Charlotte Corday, apoiante dos girondinos). O corpo de Marat jaz sobre a borda de uma banheira, onde passava grande parte do dia, fazendo banhos para alívio de uma doença cutânea pruriginosa. Não se sabe ao certo de que doença se trataria, mas é plausível suspeitar de uma dermatite atópica do adulto. Dentro das dermatoses inflamatórias, a psoríase é abordada de um modo algo dramático no filme "O detective cantor" (2003), um filme negro de Keith Gordon, em que Robert Downey Jr. interpreta o papel de um detetive privado e cantor num clube noturno que, estando internado por uma eritrodermia psoriática e sofrendo de dores intensas por uma artrite psoriática, envereda por uma série de tramas fantasiosas.

A rosácea é uma doença frequentemente representada em pintura de retrato, em que Rembrandt surge como um artista inevitável. Não só fornece um magnífico exemplo de uma rosácea eritematosa com o "Retrato de Maertgen van Bilderbeecq" (1633), como expressa a sua própria rosácea eritemato-telangiectásica num autorretrato de 1659. Ghirlandaio, pintor renascentista, fornece um exemplo de rinofima com o conhecido quadro "O velho e o seu neto". Outros exemplos pictóricos desta dermatose encontram-se em Gustav Klimt, expoente austríaco da Arte Nova, no "Retrato de uma dama" (1917) e na comédia cinematográfica "O diário de Bridget Jones" (2001), de Sharon Maguire, em que a personagem principal (Renée Zelwegger) exibe manifestações claras da doença.

A urticária é parodiada no filme "Doidos por Mary" (1998), de Bobby e Peter Farrelly, em que Dom Woganowski (Chris Elliot) desenvolve exuberantes lesões de urticária sempre que se enfurece.

Quanto à patologia tumoral (benigna e maligna), refira-se o óleo em que Goya retrata a família do rei Carlos IV. A infanta Maria Josefa, irmã do monarca, exibe uma mancha pigmentada na região temporal direita, que tanto poderia tratar-se de uma queratose seborreica como de um lentigo maligno. A presença de uma lesão compatível com um nevo celular dérmico no nariz da Bruxa Má, no filme de animação "Branca de Neve e os sete anões" (1937), de Walt Disney, é conotada a um símbolo de fealdade e de envelhecimento.

A tricologia tem uma espetacular aparição em "A muIher barbuda" (1631), um óleo do espanhol José de Ribera que retrata uma mulher barbuda a amamentar um lactente, evidenciando um hirsutismo por hiperandrogenismo. "As três idades do homem" (1510), do pintor italiano Giorgione, demonstra uma alopecia androgenética de grau VIII na escala de Hamilton. No quadro "O casamento" (1792), de Goya, encontra-se representadas uma criança com placas de alopecia areata, de acordo com a patologia provavelmente evidenciada por um modelo real utilizado pelo pintor.

As genodermatoses são alvo de múltiplas, variadas e ricas abordagens artísticas. As fotografias de retrato de Charles Eisenmann, realizadas no último quartel do século
Correspondência: Ricardo Vieira, MD, PhD

Serviço de Dermatologia

Centro Hospitalar e Universitário de Coimbra

Praceta Mota Pinto

3000-075 Coimbra

DOI: https://dx.doi.org/10.29021/spdv.78.4.1298
Recebido/Received 2020/11/05

Aceite/Accepted $2020 / 11 / 05$

Publicado/Published 2020/12/29

C Autor (es) (ou seu (s) empregador (es)) 2020 Revista SPDV. Reutilização permitida de acordo com CC BY-NC. Nenhuma reutilização comercial.

(c) Author(s) (or their employer(s)) 2020 SPDV Journal. Re-use permitted under CC BY-NC. No commercial re-use. 


\section{Editorial}

XIX e início do século XX, abrangem obsessivamente o tema de indivíduos com distúrbios aberrantes que se tornaram, por isso mesmo, artistas de feiras e de circos. Assim, na obra de Eisenmann, encontram-se exemplos de hipertricose lanuginosa congénita, de ictiose lamelar, de síndroma de Ehlers-Danlos e de cutis laxa. O filme "O homem elefante" (1981), de David Lynch, baseia-se na história real de John Merritt (representado por John Hurt), um paciente com síndroma de Proteu, seguido e estudado como suposto doente com neurofibromatose pelo cirurgião inglês Frederick Treves (representado por Anthony Hopkins). O albinismo surge no cinema quase sempre associado a personagens malévolas, como ocorre com Silas, o monge albino da Opus Dei em "O código da Vinci" (2006), de Ron Howard. Uma representação mais humana do albinismo surge nos retratos de albinos tanzanianos realizados pela fotógrafa Manrika Masséus, num projeto intitulado "Under the same sun". No filme "Os outros" (2001), de Alejandro Amenábar, Grace (Nicole Kidman) cuida dos dois filhos numa mansão, impedindo-os de se expor à luz solar, em virtude de uma doença que cursa com fotossensibilidade, hipoteticamente uma protoporfiria eritropoiética.

Nas doenças infeciosas, salienta-se uma iluminura medieval do século XIII do espólio da Biblioteca Nacional de França, pintada a têmpera sobre madeira, que representa a morte de Amalrico I de Jerusalém e a coroação de Balduíno IV, o rei leproso. O filme "O reino dos céus", realizado por Ridley Scott em 2005, mostra os estigmas da lepra lepromatosa no rei Balduíno (interpretado por Edward Norton). O sarcoma de Kaposi associado à infeção pelo VIH é representado numa cena clássica e marcante do filme "Filadélfia" (1992), de Jonathan Demme, em que Andrew Beckett (interpretado por Tom Hanks) mostra em pleno tribunal as manchas e placas violáceas características da doença.

A cosmética dermatológica encontra-se subentendida em representações do envelhecimento cutâneo, conforme observado em quadros como "As três idades da vida" (1905) de Klimt ou no retrato hiper-realista de Andrew Wyeth, intitulado Anna Christina (1967), em que o fotoenvelhecimento é uma característica profunda e marcante do sujeito retratado.

A tradição cirúrgica que embebeu a dermatologia é magnificamente evidenciada pelo pincel de Thomas Eakins. Retratando uma intervenção ortopédica realizada sob a orientação do Dr. Samuel Gross, o óleo "A clínica Gross", de 1875, contemporâneo do advento da anestesia geral, da antissepsia e da utilização de luvas cirúrgicas (que, no quadro, ainda não aparecem a uso), surge como um exemplo da modernidade que revolucionou a prática cirúrgica numa perspetiva transversal a diversas especialidades.

A venereologia é, porventura, uma das áreas do corpus da Dermatologia com presença mais interessantes em vários domínios artísticos. Exemplos particularmente interessantes são "A orgia", um óleo pintado por William Hogarth em 1734, revelador de comportamentos libertinos e promíscuos que, à época, se relacionavam com a propagação da infeção, particularmente em indivíduos da alta sociedade. Henri de Toulouse-Lautrec, que viria a morrer em consequência de uma neurossífilis, pintou alguns retratos de prostitutas na Paris oitocentista, como os quadros "A inspeção médica no prostíbulo" (1894) ou "Jane Avril à entrada do Moulin Rouge". O fotógrafo Eugène Atget retratou igualmente diversas prostitutas de Paris, como patente na fotografia "Prostitutas da Rue Asselin" (c. 1925).

A Natureza como contínuo objeto da arte e como fonte do Belo, inspirou a criação de obras pictóricas que pretensiosamente aliam o realismo ultraestrutural das biopsias cutâneas coradas pela hematoxilina-eosina com um certo abstracionismo inerente às imagens histológicas. É o que acontece numa série de pinturas em acrílico de Nick Franco, baseadas na histologia da pele normal.

Finalmente, uma referência para o inesquecível Nanni Moretti que, de modo autobiográfico, narra em "Querido diário" (1994) o seu périplo inglório por vários médicos, queixando-se de prurido sine materia, mais tarde relacionado com um linfoma de Hodgkin.

Esta curta viagem, que aqui finda, e que partiu da Dermatologia em direção à Arte, procura encontrar o lado belo e artístico que, por vezes, temos a sorte de descortinar na própria semiologia clínica. Ironicamente, a doença tem, por vezes, algo de belo. A perspetiva de que a beleza de algumas dermatoses emana provavelmente dos conceitos de beleza desenvolvidos a partir da própria arte, obriga a citar de novo Oscar Wilde: "a Vida imita a Arte, muito mais do que a Arte imita a Vida".

\section{ORCID}

Ricardo Vieira

http://orcid.org/0000-0002-5914-9171 